\title{
Investigation on the dielectric properties of pulverized oil palm frond and pineapple leaf fiber for X-band microwave absorber application
}

\begin{abstract}
This paper presents the results on dielectric properties of pulverized material based on agricultural waste namely oil palm frond and pineapple leaf fiber for microwave absorber application in the X-band frequency range. The investigation is started by identifying the pulverized materials permittivities and loss tangents using coaxial probe technique, followed by density measurement comprising the determination of bulk and solid densities. Then, by using dielectric mixture model, the solid particle dielectric properties were determined. It is observed that the air properties give quite an effect on the permittivity and loss tangent of the pulverized materials. It is also found that the lower the material density the higher material dielectric constant will be. Furthermore, the results show that, both oil palm frond and pineapple leaf fiber are potential to be X-band absorber with average dielectric constant of 4.40 and 3.38 respectively. The loss tangents for both materials were observed to be more than 0.1 which mark them as lossy materials.
\end{abstract}

Keyword: Coaxial probe technique; Dielectric mixture model; Loss tangent; Material density; Permittivity 